\title{
Blood transfusion in major non-emergency surgery: The urgent necessity to significantly decrease its indication
}

\section{Editorial}

Several large, randomized, international, controlled clinical trials have clearly demonstrated that a restrictive red blood cell transfusion strategy results in similar or improved patient outcomes compared to a more liberal strategy. ${ }^{1-4}$ There has been a tendency to diminish blood transfusion (BT), in part due to the results of these and other clinical studies, in addition, to the increased necessity to reduce medical expenditures. These facts have led to the development of initiatives that promote transfusion practice with a goal of minimizing nonindicated use. ${ }^{5-8}$ These measures are in accord with the fact that it is getting more difficult to obtain adequate donors lately, and that more people rejects allogeneic BT for several reasons.

Patient blood management strategies are designed to optimize erythropoiesis, to minimize blood loss, and to manage anemia as a means to promote the availability of blood transfusion alternatives. ${ }^{9-13}$ In order to diminish the incidence of BT it is important to correct pre-operative anemia and to reduce operative blood loss in surgical patients, and the utilization of lower hemoglobin triggers for red blood cell transfusion.

Lammi JP et al. ${ }^{14}$ studied the use of blood transfusions in 1404 patients undergoing pancreatic resections in Finland. The authors tried to improve and unify blood transfusion (BT) policies in order to decrease and optimize the use of blood products. They found no differences among high, medium and, low-volume centers in BT utilization, trigger points or the use of reserved blood units after pancreato- duodenectomy or total pancreatectomy. Although, only minor changes in BT trends were found, the lowering of the transfusion trigger point and the best use of reserved blood units occurred only in high-volume centers. ${ }^{14}$ This is already a plausible finding since there is compelling evidence indicating that BT is excessive and sometimes unnecessary worldwide. Nearly 14 million units of blood are donated annually in the USA, and about 4million people receive BT every year. ${ }^{15,16}$ Blood transfusion administration in surgical and critical care settings varies between $30-100 \%$ of patients. Lammi JP et al. ${ }^{14}$ observed that $65.9 \%$ of their study patients received BT. The mean number of red BT units was 5.22/patient (1.9-8.76). The mean trigger point for BT was an $\mathrm{Hb}$ level of $8.6 \mathrm{~g} / \mathrm{dL}$. The mean percentage of blood units used out of the reserved red blood was $63.4 \%$. We can see that the percentage of BT is still elevated, the trigger $\mathrm{Hb}$ level and the utilization of reserved blood units is also high. Although, the authors did not mention BT related complications in their study, the utilization of reserved blood is strongly associated to ischemic complications. Stored red blood cells are known to have decreased 2,3 DPG in the cell membrane, hence, they are less deformable, less likely to deliver oxygen to the tissues, and with greater tendency to produce capillary obstruction. ${ }^{16}$ On the other hand, the mechanisms responsible for the increased incidence of infectious complications are due to the immunosuppressive effects of BT. Administration of blood products causes profound negative effects on the human immune system, a condition termed transfusion-related immune modulation. ${ }^{17}$

\author{
Volume 12 Issue 5 - 2019 \\ Osmar Antonio Centurión, ${ }^{1,2}$ Juan Diosnel \\ Cáceres ${ }^{\prime}$ \\ 'Department of Health Sciences's Investigation. Sanatorio \\ Metropolitano, Paraguay \\ ${ }^{2}$ Department of Cardiology, Asunción National University, \\ Paraguay
}

Correspondence: Osmar Antonio Centurión, Professor of Medicine, Asuncion National University, Department of Health Sciences's Investigation, Sanatorio Metropolitano, Teniente Ettiene $215 \mathrm{c} /$ Ruta Mariscal Estigarribia Fernando de la Mora, Paraguay, Email osmarcenturion@hotmail.com

Received: September 22, 2019 | Published: October 03, 2019

Another reason to decrease BT is the fact that blood donations have significantly diminished mainly because of decreasing number of qualified donors. ${ }^{18}$ This fact has resulted in a shortage of blood supply in blood banks worldwide which makes it necessary to seek out new treatment options. ${ }^{19}$ Although, alternatives to BT and other treatment options exist, they are seldom utilized.

BT in major surgery was associated with worse prognosis even in patients with hematocrits as low as $21 \%$ (hemoglobin of $7 \mathrm{~g} / \mathrm{dL}$ ). The risk of death within 30 days of surgery was almost 6 times greater. Moreover, BT was found to be an independent variable for increased infections and ischemic complications, such as myocardial infarction, renal compromise and failure, and stroke. Additionally, transfused patients had prolonged mechanical ventilation, higher incidence of atrial fibrillation, longer hospital length of stay, increased costs, and higher morbidity and mortality. ${ }^{20,21}$ All of these adverse clinical events are strong reasons to try hard enough to avoid BT in major surgery.

Lammi JP et al. ${ }^{14}$ mentioned that the previous utilization of a new transfusion form and national education have been effective methods in diminishing the use of blood products in major surgery in Finland. Alternatives to allogeneic BT and No-blood program implementation will further decrease the rate of BT, and will optimize the use of blood products for their utilization in emergency hemorrhagic cases. ${ }^{22-24}$

\section{Conclusion}

In conclusion, unnecessary blood transfusions should be avoided to further reduce the risk for infection and other ischemic complications. Indeed, there is a clear medicine based evidence of the shortcomings of BT in the setting of major surgery. The evidence that $\mathrm{BT}$ carries significant risks points out to avoid BT when possible. This adverse outcome of BT is to admonish the medical community and it is a serious call for caution to accomplish a detailed and conscious revision of their routine daily medical practice. 


\section{Acknowledgments}

None.

\section{Conflicts of interest}

Author declares there are no conflicts of interest towards the article.

\section{References}

1. Hebert PC, Wells G, Blajchman MA, et al. A multicenter, randomized, controlled clinical trial of transfusion requirements in critical care Transfusion Requirements in Critical Care Investigators, Canadian Critica Care Trials Group. N Engl J Med. 1999;340(6):409-417.

2. Hajjar LA, Vincent JL, Galas FR, et al. Transfusion requirements after cardiac surgery: the TRACS randomized controlled trial. JAMA. 2010;304(14):1559-1567.

3. Carson JL, Terrin ML, Noveck H, et al. Liberal or restrictive transfusion in high-risk patients after hip surgery. N Engl J Med. 2011;365(26):24532462 .

4. Villanueva C, Colomo A, Bosch A, et al. Transfusion strategies for acute upper gastrointestinal bleeding. N Engl J Med. 2013;368(1):11-21.

5. Goodnough LT, Bach RG. Anemia, transfusion, and mortality. $N$ Engl J Med. 2001;345(17):1272-1274.

6. Vincent JL, Baron JF, Reinhart K, et al. ABC (Anemia and Blood Transfusion in Critical Care) Investigators. Anemia and blood transfusion in critically ill patients. JAMA. 2002;288(12):1499-1507.

7. Fischer D, Neb H, Choorapoikayil S, et al. Red blood cell transfusion and its alternatives in oncologic surgery - a critical evaluation. Crit Rev Oncol Hematol. 2019;134:1-9.

8. Carson JL, Grossman BJ, Kleinman S, et al. Clinical Transfusion Medicine Committee of the AABB. Red blood cell transfusion: a clinical practice guideline from the AABB. Ann Intern Med. 2012;157(1):49-58.

9. Waters JH, Ness PM. Patient blood management: a growing challenge and opportunity. Transfusion. 2011 51(5):902-903.

10. Goodnough LT, Shander A. Patient blood management. Anesthesiology. 2012;116(6):1367-1376.

11. Vamvakas EC. Reasons for moving toward a patient-centric paradigm of clinical transfusion medicine practice. Transfusion. 2013;53(4):888-901.
12. Gammon HM, Waters JH, Watt A, et al. Developing performance measures for patient blood management. Transfusion. 2011;51(11):2500-2509.

13. Simancas-Racines D, Montero-Oleas N, Vernooij RWM, et al. Quality of clinical practice guidelines about red blood cell transfusion. J Evid Based Med. 2019;12(2):113-124.

14. Lammi JP, Eskelinen M, Tuimala J, et al. Blood transfusions in major pancreatic surgery: A 10-year cohort study including 1404 patients undergoing pancreatic resections in Finland. Scan J Surg. 2019;108(3):210 215 .

15. Ratko TA, Cummings JP, Oberman HA, et al. Evidence-based recommendations for the use of WBC-reduced cellular blood components. Transfusion. 2001;41(10):1310-1319.

16. Berezina TL, Zaets SB, Morgan C, et al. Influence of storage on red blood cell rheological properties. J Surg Res. 2002;102(1):6-12.

17. Vamvakas EC. Possible mechanisms of allogeneic blood transfusionassociated postoperative infection. Transfus Med Rev. 2002;16(2):144160 .

18. Bennett-Guerrero E, Zhao Y, O'Brien SM, et al. Variation in use of blood transfusion in coronary artery bypass graft surgery. JAMA. 2010;304(14):1568-1575.

19. Sojka BN, Sojka P. The blood donation experience: self-reported motives and obstacles for donating blood. Vox Sang. 2008;94(1):56-63.

20. Murphy GJ, Reeves BC, Rogers CA, et al. Increased mortality, postoperative morbidity, and cost after red blood cell transfusion in patients having cardiac surgery. Circulation. 2007;116(22):2544-2552.

21. Chen A, Trivedi AN, Jiang L, et al. Hospital Blood Transfusion Patterns During Major Noncardiac Surgery and Surgical Mortality. Medicine. 2015;94(32):e1342.

22. Simou M, Thomakos N, Zagouri F, et al. Non-blood medical care in gynecologic oncology: a review and update of blood conservation management schemes. World J Surg Oncol. 2011;9:142.

23. Vaglio S, Prisco D, Biancofiore G, et al. Recommendations for the implementation of a Patient Blood Management programme. Application to elective major orthopaedic surgery in adults. Blood Transfus. 2016;14(1):23-65.

24. Tolich DJ, McCoy K. Alternative to blood replacement in the critically ill. Crit Care Nurs Clin North Am. 2017;29(3):291-304. 